\title{
Laparoscopic completion total gastrectomy for remnant gastric cancer: a single-institution experience
}

\author{
Sang-Yong Son $\cdot$ Chang Min Lee $\cdot$ Do-Hyun Jung • \\ Ju-Hee Lee $\cdot$ Sang-Hoon Ahn $\cdot$ Do Joong Park • \\ Hyung-Ho Kim
}

Received: 10 September 2013/Accepted: 30 December 2013/Published online: 30 January 2014

(C) The International Gastric Cancer Association and The Japanese Gastric Cancer Association 2014

\begin{abstract}
Background The aim of the present study was to evaluate the feasibility of laparoscopic completion total gastrectomy (LCTG) in patients with remnant gastric cancer.

Methods Patients who underwent completion total gastrectomy for remnant gastric cancer between May 2003 and December 2012 were divided into two groups: an open completion total gastrectomy (OCTG) group and an LCTG group. Clinicopathological data, operative data, and patient survival rates were analyzed.

Results Thirty-four remnant gastrectomies (17 OCTG and 17 LCTG) were performed. The mean time interval between the prior gastrectomy and the remnant gastrectomy was 17.2 years, and benign disease showed a longer time interval than malignancy $(30.9$ vs. 8.1 years; $p<0.0001)$. LCTG required a longer operation time than OCTG (234.4 vs. $170.0 \mathrm{~min} ; p=0.002$ ); however, there were no significant differences in the estimated blood loss, the number of retrieved lymph nodes, the time to first flatus passage, the length of hospital stay, complication rates, and postoperative analgesia between the two groups. Eight patients $(47.1 \%)$ required conversion to open surgery
\end{abstract}

S.-Y. Son - C. M. Lee - D.-H. Jung · J.-H. Lee · S.-H. Ahn ·

D. J. Park · H.-H. Kim ( $\square)$

Department of Surgery, Seoul National University Bundang Hospital, 166 Gumi-ro, Bundang-gu, Seongnam 463-707, Korea e-mail: hhkim@snubh.org

Present Address:

J.-H. Lee

Department of Surgery, Hanyang University Hospital, Seoul, Korea

D. J. Park · H.-H. Kim

Department of Surgery, Seoul National University College of Medicine, Seoul, Korea during LCTG. The median overall survival was 69.1 months. There was no difference in 5-year survival between the two groups $(p=0.085)$.

Conclusion LCTG was technically feasible; however, it showed no definitive clinical advantage over OCTG.

Keywords Gastric cancer - Remnant stomach . Laparoscopic gastrectomy

\section{Introduction}

The incidence of remnant gastric cancer is increasing due to the use of subtotal gastrectomy to treat peptic ulcer disease in the past and because of increased survival rates after radical gastrectomy for gastric cancer [1]. Remnant gastric cancer is defined as gastric cancer in the remnant stomach after partial gastrectomy for benign disease or gastric cancer [2]. The rate of remnant gastric cancer is higher after a Billroth II procedure than a Billroth I procedure, and remnant gastric cancer is caused by the continuous bathing of the gastric remnant with bile acids, resulting in repeated mucosal inflammation and regeneration [3-7]. Completion total gastrectomy with radical lymphadenectomy is the only potentially curable option for remnant gastric cancer.

Laparoscopic gastrectomy is an alternative option for the treatment of early gastric cancer, and is associated with less postoperative pain, a shorter recovery period after surgery, and fewer complications [8-11]. Recent studies suggested that the indications for this procedure be extended from locally-advanced cancer to far-advanced cancer to reflect the advances made in laparoscopic devices and techniques $[12,13]$. However, few cases of laparoscopic completion total gastrectomy (LCTG) have been reported, 
and no studies on the efficacy of laparoscopic surgery for remnant gastric cancer have been undertaken.

Therefore, the aim of this study was to evaluate the feasibility of LCTG for remnant gastric cancer, and to verify the theoretical advantages (less postoperative pain, fast postoperative recovery, and lower complication rates) of laparoscopic surgery over open completion total gastrectomy (OCTG).

\section{Materials and methods}

This study was approved by the Institutional Review Board for research using human subjects at Seoul National University Bundang Hospital (protocol registration number B1309-218-105). A database search of patients who underwent surgery for remnant gastric cancer at Seoul National University Bundang Hospital between May 2003 and December 2012 was performed from the prospectively maintained gastric cancer database and electric medical records of the hospital. Thirty-seven patients were identified, but three (two cases of combined surgery for primary colon cancer and one case of completion total gastrectomy for a missed lesion at the initial operation) were excluded. The remaining 34 patients were divided into two groups according to the initial method of approach: an OCTG group $(n=17)$ and an LCTG group $(n=17)$ (Fig. 1).
Surgical procedures

All patients were treated by a single experienced surgeon who performed more than 2,000 cases of laparoscopic gastrectomy for gastric cancer between 2003 and 2012. The laparoscopic approach was performed in informed, consenting patients with preoperative T1N0M0 to T2N0M0 stage cancer [American Joint Committee on Cancer (AJCC), 7th edition] before October 2008; since then, this indication was extended to preoperative T4aN1M0 stage. All patients underwent remnant gastrectomy with lymph node dissection, and Roux-en-Y esophagojejunostomy was performed after completion of total gastrectomy.

A five-port approach was used for the laparoscopy group. This is the same system used for patients undergoing laparoscopy-assisted total gastrectomy. The first 12-mm trocar was inserted into either the infra-umbilical area or left subcostal area using the Hasson method. A 10-mm flexible laparoscope was used and the $\mathrm{CO}_{2}$ pressure was maintained at $10-12 \mathrm{mmHg}$. An ultrasonically-activated coagulating scalpel (Harmonic Scalpel, Ethicon EndoSurgery Inc., Cincinnati, OH, USA) and LigaSure (Valleylab, Boulder, CO, USA) were used for adhesiolysis and radical lymphadenectomy. After completing the total gastrectomy, intracorporeal end-to-side esophagostomy was performed using a laparoscopic purse-string clamp (Lap-Jack, Eterne, Kyeonggi-do, South Korea) and a circular stapler. The procedure is described in detail elsewhere [14].

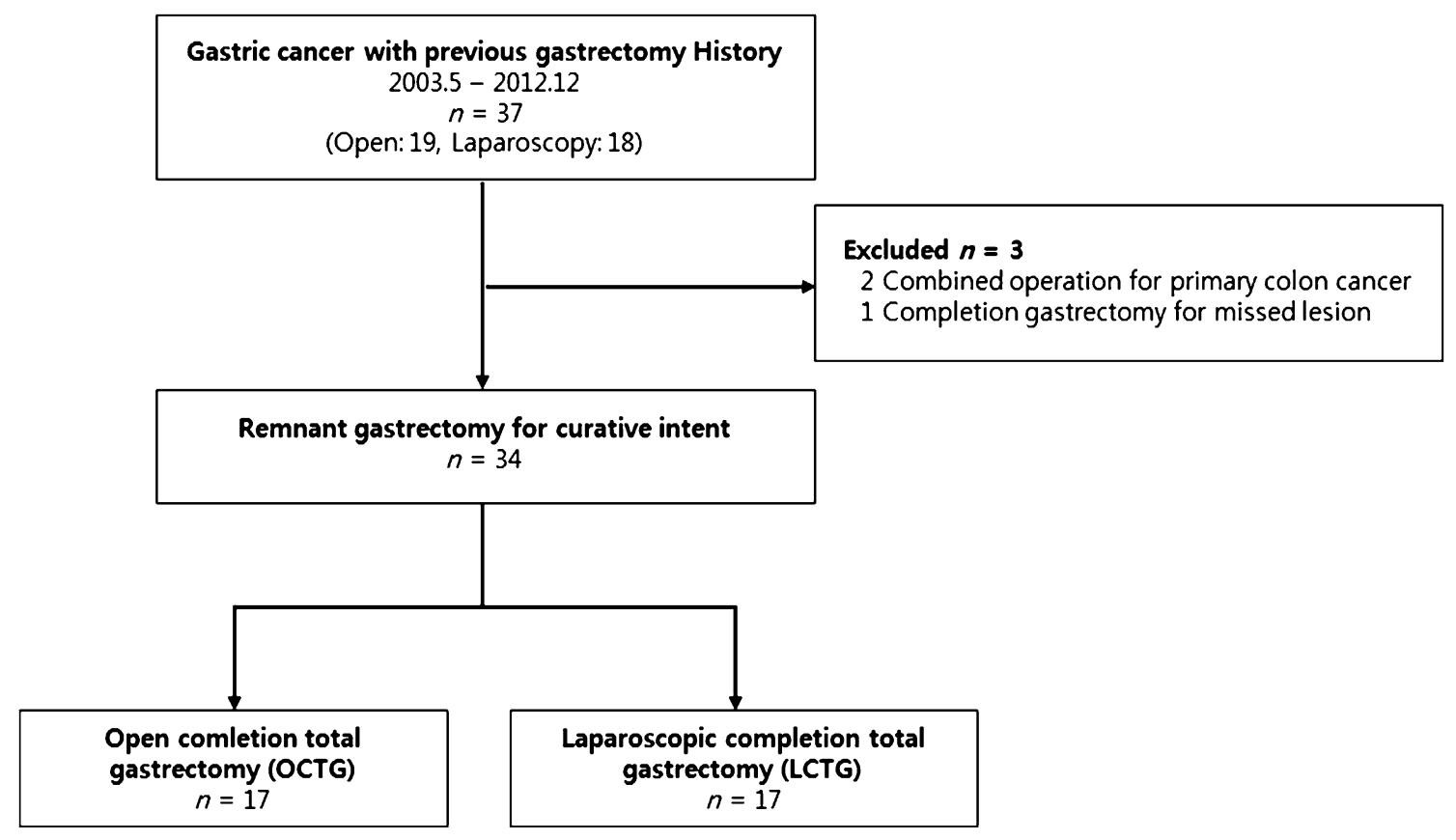

Fig. 1 Study design diagram 
Table 1 Patient characteristics

\begin{tabular}{ll}
\hline Variables & Remnant gastric cancer $(n=34)$ \\
\hline Age (years) & $66.2 \pm 10.9$ \\
Sex (M:F) & $26: 8$ \\
BMI $\left(\mathrm{kg} / \mathrm{m}^{2}\right)$ & $21.4 \pm 2.6$ \\
Comorbidity & $9(26.4 \%)$ \\
Time interval (years) ${ }^{\dagger}$ & $17.2 \pm 14.0$ \\
Benign disease $(n=13)$ & $30.9(18-45)$ \\
Malignant disease $(n=21)$ & $8.1(0.5-29)$ \\
Previous reconstruction & \\
Billroth I & $10(29.4 \%)$ \\
Billroth II & $20(58.8 \%)$ \\
(uncut) Roux en Y G-J stomy & $2(5.9 \%)$ \\
E-G stomy & $2(5.9 \%)$ \\
Tumor location & \\
Anastomotic site & $12(35.3 \%)$ \\
Body & $12(35.3 \%)$ \\
Cardia & $7(20.6 \%)$ \\
Fundus & $1(2.9 \%)$ \\
Whole stomach & $2(5.9 \%)$ \\
\hline
\end{tabular}

BMI body mass index, G-J stomy gastrojejunostomy, E-G stomy esophagogastrostomy

${ }^{\dagger} p$ value was $<0.00$

All cancers were staged according to the tumor node metastasis (TNM) classification system (7th edition), as reported by the AJCC.

Statistical analysis

All statistical analyses were performed using SPSS version 17.0 (SPSS Inc., Chicago, IL, USA). The chi-squared test, Fisher's exact test, and the Mann-Whitney $U$ test were used for comparisons between the two groups. A $p$ value of $<0.05$ was considered statistically significant.

\section{Results}

\section{Patient characteristics}

The patient characteristics are shown in Table 1 . The mean age of the patients was 66.2 years. The mean time interval between the prior gastrectomy and the development of remnant gastric cancer was 17.2 years (30.9 years in previous benign disease vs. 8.1 years in previous malignant disease, $p<0.001)$. The most common previous reconstruction method was a Billroth II anastomosis (20/34 patients, $58.8 \%$ ).

The tumor location was classified according to the modes of previous reconstruction and the original disease. The anastomotic site was the most common area of
Table 2 Short-term postoperative outcomes and pathologic results

\begin{tabular}{|c|c|c|c|}
\hline Variables & $\begin{array}{l}\text { OCTG } \\
(n=17)\end{array}$ & $\begin{array}{l}\text { LCTG } \\
(n=17)\end{array}$ & $p$ value \\
\hline Age (years) & $67.3 \pm 11.0$ & $65.1 \pm 11.1$ & 0.571 \\
\hline $\operatorname{Sex}(M: F)$ & $13: 4$ & $13: 4$ & 1.000 \\
\hline \multicolumn{4}{|l|}{ Original disease } \\
\hline Benign:malignant & $6: 11$ & $7: 10$ & 0.724 \\
\hline \multicolumn{4}{|l|}{ Previous approach } \\
\hline Open:laparoscopy & $17: 0$ & $11: 6$ & 0.006 \\
\hline \multicolumn{4}{|l|}{ Previous reconstruction } \\
\hline B-I:B-II:RY:EG & $4: 11: 1: 1$ & $6: 9: 1: 1$ & 0.663 \\
\hline Operation time (min) & $170.0 \pm 39.5$ & $234.4 \pm 65.2$ & 0.002 \\
\hline $\begin{array}{l}\text { Estimated blood loss } \\
\quad(\mathrm{ml})\end{array}$ & $184.1 \pm 123.1$ & $227.6 \pm 245.0$ & 0.518 \\
\hline Flatus passage (days) & $5.0 \pm 2.1$ & $4.6 \pm 1.4$ & 0.564 \\
\hline Hospital stay (days) & $9.3 \pm 3.1$ & $9.3 \pm 3.2$ & 1.000 \\
\hline Painkiller use $(\geq 3)$ & $1(5.9 \%)$ & $4(23.5 \%)$ & 0.172 \\
\hline $\begin{array}{l}\text { Postoperative } \\
\text { complication }^{\dagger}\end{array}$ & $5(29.4 \%)$ & $6(35.2 \%)$ & 0.533 \\
\hline$<$ IIIa & 4 & 5 & \\
\hline$\geq$ IIIa & $1^{\mathrm{a}}$ & $1^{\mathrm{b}}$ & \\
\hline Open conversion & & $8(47.1 \%)$ & \\
\hline Cost (USD) & $7461 \pm 2641$ & $9646 \pm 1784$ & 0.008 \\
\hline Number of retrieved LNs & $22.3 \pm 14.4$ & $18.8 \pm 12.3$ & 0.451 \\
\hline T-stage & & & 0.006 \\
\hline $\mathrm{T} 1$ & 4 & 11 & \\
\hline $\mathrm{T} 2$ & 3 & 3 & \\
\hline T3 & 5 & 3 & \\
\hline $\mathrm{T} 4$ & 5 & & \\
\hline $\mathrm{N}$-stage & & & 0.018 \\
\hline No & 9 & 15 & \\
\hline N1 & 4 & 2 & \\
\hline N2 & 2 & & \\
\hline N3 & 2 & & \\
\hline Stage & & & 0.105 \\
\hline IA & 4 & 11 & \\
\hline IB & 1 & 2 & \\
\hline IIA & 5 & 3 & \\
\hline IIB & 3 & 1 & \\
\hline IIIA & 1 & & \\
\hline IIIB & & & \\
\hline IIIC & 3 & & \\
\hline
\end{tabular}

$B$ - $I$ Billroth I, $B$ - $I I$ Billroth II, $R Y$ Roux en Y gastrojejunostomy, $E G$ esophagogastrostomy

${ }^{\text {a }}$ Intra-abdominal abscess

b Jejunojejunostomy site edema

$\dagger$ The Clavien-Dindo classification

remnant gastric cancer in patients that underwent Billroth II $(9 / 20,45 \%)$, and the body was the most common site in patients that underwent Billroth I $(5 / 10,50 \%)$. 
Short-term postoperative outcomes: open vs. laparoscopy

There was no statistically significant differences between the groups in terms of age, sex, the original disease, and previous reconstruction; however, the LCTG group contained six patients who had previously undergone laparoscopic gastrectomy ( $p=0.006$; Table 2).

The mean operation time was longer in the LCTG group than in the OCTG group (234 vs. $170 \mathrm{~min} ; p=0.002$ ); however, there was no significant difference in the estimated blood loss (227 vs. $184 \mathrm{ml} ; p=0.518)$, time to first flatus passage (4.6 vs. 5.0 days; $p=0.564$ ), length of postoperative hospital stay (9.3 vs. 9.3 days; $p=1.000$ ), or postoperative analgesia more than three times [4 $(23.5 \%)$ vs. $1(5.9 \%) ; p=0.172]$. The mean number of retrieved lymph nodes was 22.3 for the OCTG group and 18.8 for the LCTG group. The difference was not significant ( $p=0.451)$. The mean cost of hospital stay and operation was higher in the LCTG group than in the OCTG group (7461 USD vs. 9646 USD; $p=0.008$ ).

Because there were eight cases of open conversion in the LCTG group, we reclassified the OCTG groups such that it included patients that required an open conversion ( $r$ OCTG) and reclassified the LCTG group such that it only included patients that did not require open conversion $(r$ LCTG) (Table 3). The estimated blood loss in the $r$-LCTG group was less than that in the $r$-OCTG group (246.4 vs. $93.3 \mathrm{ml} ; p=0.002)$; however, there was no difference in the mean operation time (195 vs. $222 \mathrm{~min} ; p=0.250$ ), the time of flatus passage ( 5.0 vs. 4.2 days; $p=0.259$ ), length of hospital stay (9.5 vs. 8.8 days; $p=0.687$ ), or complication rates $(28.0$ vs. $44.4 \% ; p=0.300)$. The number of retrieved lymph nodes was not significantly different between the reclassified groups (19.8 vs. $22.7 ; p=0.575)$.

There was no significant difference in morbidity between the OCTG group (29.4\%) and the LCTG group (35.2\%) ( $p=0.533)$. Two patients suffered major complications ( $\geq$ grade IIIa according to the Clavien-Dindo classification). One OCTG patient developed an intraabdominal abscess in the sub-phrenic area, which was treated by percutaneous drainage. One LCTG patient developed edema at the site of jejunojejunostomy; however, this improved after a percutaneous transhepatic biliary drain was inserted to relieve the reflux cholangitis. None of the patients died.

Eight patients in the LCTG group required open conversion. The most common reason for open conversion was the presence of severe adhesions (Table 4). Five out of six LCTG patients who had previously undergone laparoscopic gastrectomy required conversion to open surgery, as did six out of eight patients who had previously undergone gastrectomy due to malignant disease. Laparoscopic surgery
Table 3 Comparison of postoperative outcomes in the reclassified groups

\begin{tabular}{|c|c|c|c|}
\hline Variables & $\begin{array}{l}r \text {-OCTG } \\
(n=25)\end{array}$ & $\begin{array}{l}r \text {-LCTG } \\
(n=9)\end{array}$ & $p$ value \\
\hline Operation time (min) & $195.1 \pm 64.2$ & $222.0 \pm 55.4$ & 0.250 \\
\hline $\begin{array}{l}\text { Estimated blood loss } \\
(\mathrm{ml})^{\S}\end{array}$ & $246.4 \pm 208.4$ & $93.3 \pm 51.9$ & 0.002 \\
\hline Flatus passage (days) & $5.0 \pm 1.8$ & $4.2 \pm 1.3$ & 0.259 \\
\hline Hospital stay (days) & $9.5 \pm 2.7$ & $8.8 \pm 4.2$ & 0.687 \\
\hline Painkiller use $(\geq 3)$ & $4(17.4 \%)$ & $1(12.5 \%)$ & 1.000 \\
\hline $\begin{array}{l}\text { Postoperative } \\
\text { complication }\end{array}$ & $7(28.0 \%)$ & $4(44.4 \%)$ & 0.300 \\
\hline $\begin{array}{l}\text { Number of retrieved } \\
\text { LNs }\end{array}$ & $19.8 \pm 13.4$ & $22.7 \pm 13.8$ & 0.575 \\
\hline
\end{tabular}

\footnotetext{
$\$$ Without open conversion cases: estimated blood loss was $184.1 \pm 123.1 \mathrm{ml}$ in OCTG and $93.3 \pm 51.9 \mathrm{ml}$ in LCTG, retrospectively $(p=0.047)$
}

was successful in $71.4 \%(5 / 7)$ of patients with previous benign disease, and in $40.0 \%$ (4/10) in patients with previous malignant disease, but the difference was not significant $(p=0.335)$.

Survival after completion total gastrectomy

The mean duration of follow-up was 30.5 months (37.3 months for the OCTG group vs. 23.6 months for the LCTG group; $p=0.163$ ). The median overall survival was 69.1 months and the 5-year survival rate was $66.6 \%$. There was no difference in 5-year survival between the two groups $(60.3 \%$ in the OCTG vs. $66.7 \%$ in the LCTG; $p=0.085)$.

Seven patients died during the follow-up period: three due to recurrence (all in the OCTG group) and four from other diseases (three OCTG patients and one LCTG patient). One patient is alive with recurrent disease. None of the patients developed local recurrence.

\section{Discussion}

Yamada et al. [15] first reported a case of laparoscopyassisted resection of gastric remnant cancer in a patient who had undergone a previous Billroth II reconstruction in 2005. In 2010, Park et al. [16] reported nine cases of laparoscopy-assisted resection, including two patients that had previously undergone a Billroth I reconstruction. Shinohara et al. [17]were the first to report a series of patients that underwent total LCTG. All of these studies showed the feasibility of laparoscopic surgery, even though there was technical difficulty due to adhesions around the previous anastomosis. Some studies reported less estimated blood loss and faster recovery of bowel movement after LCTG. 
Table 4 Clinical characteristics of the open conversion cases in the laparoscopic group

\begin{tabular}{|c|c|c|c|c|c|c|c|c|c|}
\hline Case & Age/sex & BMI & $\begin{array}{l}\text { Original } \\
\text { disease }\end{array}$ & $\begin{array}{l}\text { Previous } \\
\text { approach }\end{array}$ & $\begin{array}{l}\text { Previous } \\
\text { reconstruction }\end{array}$ & $\begin{array}{l}\text { Reason of open } \\
\text { conversion }\end{array}$ & $\begin{array}{l}\text { Operation time } \\
(\min )\end{array}$ & $\begin{array}{l}\text { Blood loss } \\
(\mathrm{ml})\end{array}$ & $\begin{array}{l}\text { Hospital stay } \\
\text { (days) }\end{array}$ \\
\hline 1 & $63 / \mathrm{M}$ & 20.4 & Benign & Open & Billroth I & Severe adhesion & 135 & 150 & 7 \\
\hline 2 & $56 / \mathrm{M}$ & 24.0 & Benign & Open & Billroth II & Severe adhesion & 390 & 1000 & 11 \\
\hline 3 & 64/M & 22.0 & Malignant & Laparoscopy & Billroth I & Severe adhesion & 200 & 300 & 9 \\
\hline 4 & $66 / \mathrm{M}$ & 23.3 & Malignant & Laparoscopy & Billroth I & Bleeding & 250 & 500 & 12 \\
\hline 5 & 71/M & 25.5 & Malignant & Laparoscopy & Billroth I & Severe adhesion & 225 & 130 & 10 \\
\hline 6 & $75 / \mathrm{F}$ & 19.8 & Malignant & Laparoscopy & Billroth I & Severe adhesion & 285 & 500 & 10 \\
\hline 7 & $80 / \mathrm{M}$ & 24.5 & Malignant & Open & Billroth II & Severe adhesion & 210 & 150 & 8 \\
\hline 8 & $38 / \mathrm{F}$ & 22.3 & Malignant & Laparoscopy & Uncut Roux en Y & Severe adhesion & 293 & 300 & 12 \\
\hline
\end{tabular}

However, there was no comparative study on the efficacy of LCTG for remnant gastric cancer.

There is no consensus regarding the use of a laparoscopic approach for completion total gastrectomy; however, we performed an open conversion in eight cases, mostly due to the presence of severe adhesions. Therefore, the use of laparoscopy for completion total gastrectomy should be considered in patients with mild adhesions.

Overall, several factors should be considered when selecting potential cases for laparoscopic surgery. First, the type of the original disease might be a major cause of severe adhesions. For example, in contrast to benign disease, radical lymphadenectomy is mandatory in the case of malignant disease, and this may result in complicated and confused adhesions around the site of the previous operative bed. We noted that laparoscopic surgery was more successful for patients with previous benign disease than for those with previous malignant disease, although the difference did not reach statistical significance.

Yamada et al. [15] stated that technical difficulties may arise in patients that had undergone a previous Billroth I reconstruction. This is because firm fibrous adhesions forms around adjacent organs such as the liver and pancreas. Here, we performed open conversions in five out of six patients with a previous Billroth I reconstruction, and observed severe adhesions between the site of gastroduodenostomy and the pancreatic head or the liver, even in those that had undergone laparoscopy-assisted distal gastrectomy.

Conversely, the previous approach does not appear to be the deciding factor when choosing LCTG. Laparoscopic surgery can reduce the formation of adhesions between the abdominal wall and intra-abdominal organs, but it does not appear to reduce the formation of adhesions around the operative bed, especially at the anastomotic site. Five of the open conversions in the present study were performed in patients who had undergone previous laparoscopyassisted distal gastrectomy for gastric cancer, and only one patient that had previously undergone laparoscopy-assisted proximal gastrectomy underwent successful LCTG.
Therefore, the patient who underwent subtotal gastrectomy with previous Billroth II reconstruction for benign disease may have been a good candidate for the laparoscopic approach in remnant gastric cancer, based on our experience.

The extent of lymph node dissection required during LCTG has not been established, but the Japanese gastric cancer guidelines recommend radical lymphadenectomy with complete resection of the remnant stomach for patients undergoing an open procedure [18]. Regarding the number of retrieved lymph nodes, there was no difference between the open and laparoscopy groups (22.3 vs. 18.8; $p=0.451$ ). Similarly, there was no difference in survival between the two groups, despite the heterogeneity of the tumor stages. Thus, although the laparoscopic procedure for remnant gastric cancer seems to be acceptable in earlystage gastric cancer, further robust clinical studies and the collection of large-scale data are still required.

We also found that the mean operation time for LCTG was longer that for OCTG, and that the procedure resulted in a higher conversion rate; however, there were no significant differences in estimated blood loss, length of hospital stay, time to first flatus passage, and complication rates.

Because there were eight cases of open conversion in the LCTG group, we reclassified the OCTG group such that it included patients that required an open conversion $(n=25)$ and reclassified the LCTG group such that it only included patients that did not require open conversion $(n=9)$. We then reanalyzed the data. The estimated blood loss in the reclassified LCTG group was less than that in the reclassified OCTG group; however, there was no difference in the time of flatus passage, length of hospital stay, or complication rates. Thus, in contrast to previous reports, we concluded that LCTG is feasible in terms of technique, but it has no definitive benefits over the open procedure. However, when interpreting the results of the present study, we must bear in mind the limitations. The study had a retrospective design and the sample size was small. Therefore, multi-center studies and/or meta-analysis should be considered to verify the putative advantages of LCTG. 
In summary, we found that LCTG for remnant gastric cancer is technically feasible. However, the operation time and open conversion rate are both higher. Thus, LCTG has no definitive clinical advantages over the open procedure. This means that immediate open conversion should be considered if a critical intraoperative event, such as injury to a major vessel or organ, occurs during LCTG.

Conflict of interest Sang-Yong Son, Chang Min Lee, Do-Hyun Jung, Ju-Hee Lee, Sang-Hoon Ahn, Do Joong Park, and Hyung-Ho Kim have no conflicts of interest or financial ties to disclose.

\section{References}

1. Sinning C, Schaefer N, Standop J, Hirner A, Wolff M. Gastric stump carcinoma-epidemiology and current concepts in pathogenesis and treatment. Eur J Surg Oncol. 2007;33:133-9.

2. Tanigawa N, Nomura E, Niki M, Shinohara H, Nishiguchi K, Okuzawa M, et al. Clinical study to identify specific characteristics of cancer newly developed in the remnant stomach. Gastric Cancer. 2002;5:23-8.

3. Lundegardh G, Adami HO, Helmick C, Zack M, Meirik O. Stomach cancer after partial gastrectomy for benign ulcer disease. N Engl J Med. 1998;319:195-200.

4. Arnthorsson G, Tulinius H, Egilsson V, Sigvaldason H, Magnusson B, Thorarinsson H. Gastric cancer after gastrectomy. Int J Cancer. 1998;42:365-7.

5. Caygill CP, Hill MJ, Kirkham JS, Northfield TC. Mortality from gastric cancer following gastric surgery for peptic ulcer. Lancet. 1986;1:929-31.

6. Tersmette AC, Offerhaus GJ, Tersmette KW, Giardiello FM, Moore GW, Tytgat GN, et al. Meta-analysis of the risk of gastric stump cancer: detection of high risk patient subsets for stomach cancer after remote partial gastrectomy for benign conditions. Cancer Res. 1990;50:6486-9.

7. Moller H, Toftgaard C. Cancer occurrence in a cohort of patients surgically treated for peptic ulcer. Gut. 1991;32:740-4.
8. Lee SI, Choi YS, Park DJ, Kim HH, Yang HK, Kim MC. Comparative study of laparoscopy-assisted distal gastrectomy and open distal gastrectomy. J Am Coll Surg. 2006;202:874-80.

9. Hwang SH, Park DJ, Jee YS, Kim MC, Kim HH, Lee HJ, et al. Actual 3-year survival after laparoscopy-assisted gastrectomy for gastric cancer. Arch Surg. 2009;144:559-64.

10. Kim HH, Hyung WJ, Cho GS, Kim MC, Han SU, Kim W, et al. Morbidity and mortality of laparoscopic gastrectomy versus open gastrectomy for gastric cancer: an interim report-a phase III multicenter, prospective, randomized Trial (KLASS Trial). Ann Surg. 2010;251:417-20.

11. Lee JH, Park do J, Kim HH, Lee HJ, Yang HK. Comparison of complications after laparoscopy-assisted distal gastrectomy and open distal gastrectomy for gastric cancer using the ClavienDindo classification. Surg Endosc. 2012;26:1287-95.

12. Lee JH, Son SY, Lee CM, Ahn SH, Park DJ, Kim HH. Morbidity and mortality after laparoscopic gastrectomy for advanced gastric cancer: results of a phase II clinical trial. Surg Endosc. 2013;27:2877-85.

13. Son SY, Lee CM, Lee JH, Ahn SH, Kim JW, Lee KU, et al. Laparoscopy-assisted gastrectomy with para-aortic lymphadenectomy after palliative chemotherapy for advanced gastric cancer with isolated para-aortic lymph node metastasis. J Korean Surg Soc. 2013;84:304-8.

14. Lee JH, Ahn SH, Park do J, Kim HH, Lee HJ, Yang HK. Laparoscopic total gastrectomy with D2 lymphadenectomy for advanced gastric cancer. World J Surg. 2012;36:2394-9.

15. Yamada H, Kojima K, Yamashita T, Kawano T, Sugihara K, Nihei Z. Laparoscopy-assisted resection of gastric remnant cancer. Surg Laparosc Endosc Percutan Tech. 2005;15:226-9.

16. Park JH, Lee YJ, Jeong CY, Ju YT, Jung EJ, Hong SC. The laparoscopic approach for gastric remnant cancer. J Korean Surg Soc. 2008;74:418-23.

17. Shinohara T, Hanyu N, Tanaka Y, Murakami K, Watanabe A, Yanaga K. Totally laparoscopic complete resection of the remnant stomach for gastric cancer. Langenbecks Arch Surg. 2013;398:341-5.

18. Japanese Gastric Cancer A. Japanese classification of gastric carcinoma-2nd English edition. Gastric Cancer. 1998;1:10-24. 